\title{
O Clube do Bangue-Bangue e as imagens do fim do apartheid: o papel político do fotógrafo
}

\section{The Bang-Bang Club and the images of the end of apartheid: the political role of the photographer}

\author{
Renata de Paula dos Santos ${ }^{1}$
}

\section{Resumo}

Este artigo pretende contribuir com a análise do papel do repórter fotográfico na cobertura de guerras. Partindo da premissa de que a fotografia não se trata de um meio de comunicação neutro, a pesquisa avalia o posicionamento de Greg Marinovich - membro do chamado Clube do Bangue-Bangue - durante a Guerra dos Albergues. Esse confronto ocorreu na África do Sul, entre os anos 1990 e 1994, constituindo a fase final do regime do apartheid, iniciado em 1948. Três fotografias tomadas em 1990 compõem o corpus da pesquisa. Como método para condução da análise, foi utilizada a pesquisa historiográfica. Entre os autores que conduzem o trabalho, destacam-se Demétrio Magnoli (1998) e Marinovich e João Silva (2003), na questão sul-africana, e Boris Kossoy (1989) no campo da fotografia. Como resultado preliminar, apresenta-se a forte oposição do fotógrafo ao Estado branco.

Palavras-chaves: África do Sul. Apartheid. Clube do Bangue-Bangue. Papel político do fotógrafo.

\begin{abstract}
This article aims to analyze the role of the photojournalist covering wars. On the premise that photography is not a neutral medium, the research seeks to evaluate the positioning of Greg Marinovich - member called Bang-Bang Club - during the War of hostels. This confrontation took place in South Africa between the years 1990 and 1994, representing the final stage of the apartheid regime, inserted in 1948. Three photographs taken in 1990 comprise the corpus of research. As a method for conducting analysis was used to search historiographical. Among the authors highlight the work leading up Demétrio Magnoli (1998) and Marinovich and João Silva (2003), the South African issue, and Boris Kossoy (1989) in the field of photography. As a preliminary result, it presents the photographer's strong opposition to white rule.
\end{abstract}

Keywords: South Africa. Apartheid. Bang-Bang Club. Political role of the photographer.

\footnotetext{
${ }^{1}$ Graduada em Comunicação Social - Jornalismo pela Universidade Estadual de Londrina (UEL). Mestranda em Comunicação pela mesma instituição. Bolsista da Capes. Email: renatapstos@hotmail.com.
} 


\section{Introdução}

Para entender a ação do Clube do BangueBangue, é preciso conhecer, anteriormente, a realidade sociopolítico-cultural da África do Sul e os mecanismos que determinaram a manutenção do apartheid - entre eles, o apoio internacional para o desenvolvimento da economia e a negação plena da cidadania aos negros.

A segregação racial começou ainda na colonização, teve seu ápice com a instauração do apartheid, em 1948, e permanece até os dias atuais. Segundo Magnoli (1998), foi o sistema políticoeconômico da África do Sul, baseado na divisão da cor da pele (apartheid significa desenvolvimento separado) que comprometeu todo o aspecto social do país e gerou o clima de instabilidade. Os últimos anos do regime (1990-1994) foram marcados por intensos conflitos entre as tribos negras. Em quatro anos, cerca de 14 mil sul-africanos foram mortos. (MARINOVICH; SILVA, 2003).

É neste contexto que Greg Marinovich integrou o Clube do Bangue-Bangue, ao lado de Ken Oosterbroek, Kevin Carter e João Silva. Em meio a uma guerra, qual o papel político do fotógrafo? É a problemática que este artigo tenta abordar: qual foi o posicionamento de Marinovich diante dos últimos anos do apartheid?

A fotografia, enquanto meio de comunicação, é formada pela tríade emissor - meio - receptor; entretanto, não é possível ignorar a leitura que o fotógrafo faz do fato. Assim como a escrita, a imagem fotográfica é o resultado da interpretação do repórter diante da realidade.

A fotografia não se trata de um retrato fiel e isento da realidade, mas de um recorte opinativo e passível de manipulações (KOSSOY, 1989). O registro imagético documenta as pessoalidades do fotógrafo, o que ele viu e o que pensa ter visto. (MARTINS, 2008).

Para o desenvolvimento da análise, foram escolhidas três fotografias de 1990. As imagens documentam o assassinato de dois sul-africanos que ganharam destaque no cenário internacional. Analisar o trabalho do Clube do Bangue-Bangue, mas especificamente de Greg Marinovich, é relevante pela importância que o grupo alcançou no universo do fotojornalismo e pela complexidade dos fatos representados. O método escolhido para o desenvolvimento deste artigo foi a pesquisa historiográfica.

Entre os autores que conduzem o trabalho, destacam-se Magnoli (1998) e Marinovich e Silva (2003), na questão sul-africana, e Kossoy (1989) no campo da fotografia. Como resultados preliminares, apresentam-se a forte oposição dos fotógrafos ao Estado branco e a força que as fotografias ganharam na imprensa internacional.

\section{África do Sul e a Consolidação do Apartheid}

A consolidação do apartheid como medida de governo data de 1948. O sistema, que permaneceu em vigor até $1994^{2}$, teve inspirações no conceito nazista de supremacia racial. Para o autor Demétrio Magnoli (1998), capitalismo e apartheid eram realidades diretamente ligadas.

Entre os anos 1948 e 1966, o sistema de segregação racial ficou conhecido como Pequeno apartheid. Esse período caracterizou-se como a série inicial de medidas governamentais para a

\footnotetext{
${ }^{2}$ Para efeitos metodológicos, o sistema de governo será dividido em quatro grandes fases, começando pelo Pequeno apartheid, entre os anos 1948 e 1966, seguido pelo Grande apartheid, de 1966 a 1984, Neo-apartheid, de 1984 a 1990, e a Guerra dos Albergues, entre os anos 1990 e 1994.
} 
demarcação do território entre brancos e negros. A separação geográfica tornou-se uma barreira à integração econômica dos negros, tendo em vista que essa população ocupou as áreas mais periféricas do país. A primeira medida legal tomada pelo governo foi a Lei de Proibição de Casamentos Mistos (Prohibition of Mixed Marriages Act), de 1949. A medida interditava o matrimônio entre pessoas racialmente distintas. Na prática, o governo pretendia evitar o contato entre brancos e negros e reduzir o número de mestiços.

Em 1950, com o decreto da Lei de Registro da População (Population Registration Act), os sul-africanos foram classificados de acordo com aspectos raciais e linguísticos. (MAGNOLI, 1998). Com essa medida, a população foi dividida em brancos, negros, mestiços e asiáticos. Era por meio dessa lei, que o Governo Africânder realizava a distribuição dos benefícios sociais. A redução ocorria de acordo com a cor da pele; nos extremos, situavam-se os brancos (com a cidadania plena) e os negros (nenhuma forma de representação política, subempregos e condições precárias de educação e moradia). Segundo Carlin (2009), em ordem decrescente de privilégios estavam os brancos, mestiços, indianos (asiáticos) e negros.

O passo seguinte para o fortalecimento do apartheid ocorreu ainda em 1950, com a Lei das Áreas de Grupo (Group Areas Act). Por meio dessa determinação, posta em vigor 16 anos depois, tornava-se proibida a residência de habitantes em áreas destinadas a outros grupos étnicos. Em 1952, a medida foi intensificada com a Lei de Circulação dos Nativos (Native Act). Por meio dessa sanção política, tornou-se obrigatório o porte de autorizações (passe ou passaporte) para a circulação em territórios em que o indivíduo não habitasse.

Datam desse período, ainda, a Lei da Educação Negra (Black Education Act), de 1953, e a Lei de Serviços Públicos Separados (Reservation of Separate Act), também de 1953. Em 1957, com a Lei da Imoralidade (Immorality Amendment Act), tornaram-se crimes relações sexuais entre indivíduos racialmente distintos. Essa medida, combinada com a oferta de serviços públicos separados, visava dificultar o estabelecimento de famílias interraciais.

O Grande apartheid (1966 - 1984) apresentouse como uma série de práticas de segregação mais desenvolvidas e ambiciosas. Em 1971, foi implementada a Lei de Constituição das Pátrias Banto (Bantu Homelands Constitution Act). Tal medida dividiu o território sul-africano em dez áreas, chamadas bantustões ou homelands, afastando os negros, definitivamente, das áreas centrais. O objetivo dessa lei foi o de fragmentar a população negra em diversas áreas circundantes à nação africânder. Com a subdivisão, a possibilidade de mobilização foi enfraquecida, bem como das manifestações culturais. Os bantustões foram pilares importantes no desenvolvimento do apartheid, mecanismo para a formação de um Estado branco, plenamente desenvolvido e estabelecido na classificação racial. Segundo Magnoli (1998), durante o auge do regime, mais da metade da população negra habitava os distritos raciais.

Foi durante o Grande apartheid (1966-1984) que a África do Sul apresentou intenso desenvolvimento econômico. A população branca gozava de qualidade de vida semelhante aos países europeus. Nas palavras de Carlin (2009), a desigualdade social sul-africana pode ser descrita da seguinte forma:

\footnotetext{
Uma seca, um labirinto apinhado de casas que pareciam caixas de fósforos numa vastidão reta e árida; a outra era um oásis criado pelo homem, com salgueiros-chorões, gramados verdes como campos de golfe, jardins de rosas cuidadosamente tratados e grandes casas cujos donos não se intimidavam em sugar recursos do rio Orange, que corria ao lado. Upington poderia ter sido quase mais graciosa, se fosse menos artificial, se todo aquele verde não parecesse uma ornamentação falsa em meio ao calor sufocante e à monotonia do deserto em torno, se não fosse um lugar onde os brancos rotineiramente chamassem os negros de nomes vergonhosos e ultrajantes como kaffir - a versão sul-africana para o ofensivo nigger dos Estados Unidos (CARLIN, 2009, p. 48-49).
} 
A derrocada do apartheid teve início na década de 1980, pelos excessos do próprio sistema e pela pressão internacional. Os anos de 1984, 1985 e 1986 foram marcados por grandes mobilizações, manifestações e greves de militantes contrários ao governo vigente. A instabilidade política sul-africana e a crise política internacional foram responsáveis pela insuficiência do sistema.

Entre as décadas de 1980 e 1990, o apartheid entrou em declínio, o que representou a flexibilização de algumas medidas por parte do governo. O Neoapartheid (1984-1990) visava, a todo custo, impedir que a maioria numérica dos negros se convertesse em força política. Para isso, Magnoli (1998) descreve que o, então, presidente do país, Pieter W. Botha, estava disposto a reduzir o abismo social em que o sistema se desenvolvera. Essa atitude seria um meio de manter o Estado Africânder no poder, ainda que mais enfraquecido.

A libertação de Nelson Mandela, em fevereiro de 1990, representou a pressão internacional a que a África do Sul estava imposta. Além das questões políticas, o país estava proibido de participar de competições esportivas internacionais e submetido a embargos econômicos norte-americanos.

A estrutura do apartheid culminou na construção de um país socialmente destruído. A intolerância não apenas separou brancos e negros, mas propiciou o enfretamento entre as diversas tribos negras. A guerrilha dava-se principalmente entre os zulus, militantes do Partido da Liberdade Inkatha (PLI), liderado por Mangosuthu Buthelezi, e os xhosas, partidários do Congresso Nacional Africano (CNA), partido de Mandela. O intervalo entre os anos 1990 e 1994, período em que os órgãos de oposição iniciaram o processo de transição política, ficou conhecido como Guerra dos Albergues e culminou em 14 mil mortes. (MARINOVICH ; SILVA, 2003). A violência constante e o apoio do Governo Africânder ao Inkatha ${ }^{3}$ tornaram as áreas de acesso entre os distritos zulu e xhosa intrafegáveis. Foi nesse período em que Greg Marinovich, Ken Oosterbroek, Kevin Carter e João Silva - o Clube do Bangue-Bangue - estiveram na região. Nos relatos do grupo,

\section{Milhares de membros do Inkatha foram treinados em tática de guerra pela polícia e pela direita em campos secretos. Líderes do Inkatha recebiam armas e dinheiro de unidades policiais secretas. Policiais brancos e negros ou membros das forças especiais eram vistos com frequência com agressores do Inkatha, e um policial branco chegou a depor, anos mais tarde, que participara de ataques em trens suburbanos disfarçado de negro e que mais tarde retornara ao local como investigador (MARINOVICH; SILVA, 2003, p. 111).}

Com a eleição de Nelson Mandela para a presidência da República, em 1994, o apartheid chegou ao fim. Com a criação da Comissão de Reconciliação e Verdade, proposta pelo novo governo, responsável por apurar o passado sulafricano, foi reconhecida a existência de diversos crimes cometidos por zulus e xhosas. O apoio estatal conferiu ao Inkatha a responsabilidade por um terço de todas as violações ocorridas nos conflitos. Segundo Marinovich e Silva (2003), para cada partidário do Inkatha morto, três do CNA perderam a vida.

\section{As Diversas Expressões do Nacionalismo Sul-Africano}

Mesmo antes da instauração do apartheid, o voto censitário excluía a população negra, asiática e mestiça dos processos eleitorais e dos espaços de decisão, apesar do país estar inserido em um universo pluripartidarista. Com o início do apartheid, os

${ }^{3}$ O jornalista norte-americano Jonh Carlin (2009) classifica o Inkatha como a direita negra. A relação entre o Estado e o grupo tinha o intuito de atrasar a realização da primeira eleição multirracial e enfraquecer a candidatura de Nelson Mandela. 
partidos de oposição tornaram-se ilegais. Na década de 1940, as expressões mais marcantes da realidade política sul-africana era o grupo branco, com nacionalismo africânder, e a militância negra por meio do Congresso Nacional Sul-Africano.

O objetivo dos africânderes era criar um Estado branco, semelhante ao proposto por Adolf Hitler, na Alemanha Nazista, fundamentado nas glórias passadas e na tradição de seu povo. Uma das bandeiras mais fortes do movimento eram os preceitos anticomunistas.

O CNA era composto por representantes das famílias reais sul-africanas, em sua maioria, advogados, médicos e religiosos anglicanos. O nacionalismo negro, marcado por forte influência do liberalismo inglês, tinha como base o progresso e o desenvolvimento das cidades. A principal meta do partido, enquanto movimento político, era sentarse com o governo vigente para discutir as medidas discriminatórias estatais.

O Grande apartheid (1966 - 1984) foi o período em que o país se consolidou como potência sulafricana, graças aos melhores índices econômicos e de desenvolvimento. Entretanto, o continente não era unânime, quanto à manutenção do sistema excludente de governo. O crescimento da república sul-africana e sua posição de liderança regional eram as formas encontradas pelo governo para impedir que o CNA se vinculasse a países africanos independentes. Desde 1961, o partido desenvolvia atos de sabotagem contra o sistema vigente.

Durante o apartheid, Soweto tornou-seum distrito particular, um território de forte resistência, o berço do nacionalismo negro. Em meados da década de 70, os movimentos negros ${ }^{4}$ sofriam forte influência das revoluções ocorridas em Moçambique, Angola e Rodésia (atual Zimbábue). O distrito contava com mais de um milhão de habitantes e "a atmosfera pesava como chumbo”, (MAGNOLI, 1998, p. 62), em clima de desobediência e revolução.

Com a libertação de Mandela, Carlin (2009) pondera que o mais estranho a qualquer estrangeiro que visitasse o país não era a divisão (incitada pelo apartheid) entre direita (governo africânder) e esquerda (CNA e demais movimentos negros), mas a existência de uma direita negra. Para exemplificar tal situação, o autor narra a relação entre o partido negro Inkatha e seu líder Mangosuthu Buthelezi com Pieter Botha. Nas palavras do autor:

O pequeno estado de Buthelezi seria cômico, se não fosse uma ferramenta de Botha para conter a insurgência do povo. Orientado pelo brigadeiro do governo em Pretória, Buthelezi despachou suas forças impi (palavra em zulu para 'batalhão') contra a metade da população zulu urbana, que falava inglês e que apoiava o CNA, resultando em batalhas entre os dois lados que causaram milhares de mortes. O CNA e seus apoiadores acabaram detestando Buthelezi tanto quanto Botha, se não mais. Buthelezi temia, se Mandela um dia tomasse o poder, perder os privilégios políticos e econômicos derivados de sua cumplicidade com o Estado do apartheid. Ele também temia uma vingança sangrenta, assim como a direita branca, razão pela qual nenhum dos dois via qualquer benefício num processo de negociação cujo fim fosse um governo majoritário (CARLIN, 2009, p. 119).

No período em que a instabilidade social assumiu os índices mais alarmantes no país, o Clube do Bangue-Bangue iniciou os seus registros na África do Sul. Seria impossível, neste artigo, apresentar todo o trabalho desenvolvido pelo grupo durante os quatro anos, para isso, buscaremos imagens e relatos documentados por Greg Marinovich e João Silva (2003) em O Clube do Bangue-Bangue: instantâneos de uma guerra oculta.

\footnotetext{
${ }^{4}$ A expressão movimentos negros refere-se a outras mobilizações políticas de origem negra e com intuito libertário, que não o CNA.
} 


\section{A subjetividade Fotográfica}

Partindo da premissa de que a fotografia é um recorte espaço-temporal da realidade (BONI, 2000), conclui-se que esse meio é composto por características opinativas. O elemento fotográfico é intencional e permeado por marcações estéticas que refletem a opinião do emissor.

Ao entrar em contato com uma fotografia, o leitor se depara, simultaneamente, com a interpretação do fotógrafo diante do fato. Nessa perspectiva, Kossoy (1989) conceitua que, além do registro visual documentar uma parcela da realidade, ele registra, também, o estado de espírito de seu emissor naquele momento. Uma fotografia se refere não só ao fato em si, mas aos sentimentos, aos desejos e à ideologia do fotógrafo. Com a fixação da imagem no suporte, a interpretação do emissor estará imortalizada. Cada imagem fotográfica é o resultado de um processo específico, motivado por um contrato, por um desejo ou por qualquer outra razão.

Ao submeter dois fotógrafos ao mesmo cenário, é sabido que os registros imagéticos serão distintos, já que a fotografia é composta pelos interesses individuais do emissor. Assim como os demais meios de comunicação, o emissor age como um filtro cultural.

Toda e qualquer fotografia, além de ser resíduo do passado, é também um testemunho visual onde se pode detectar - tal como ocorre nos documentos escritos - não apenas os elementos constitutivos que lhe deram origem do ponto de vista material. No que toca à imagem fotográfica, uma série de dados poderá ser revelada, posto que jamais mencionada pela linguagem escrita da história. Por outro lado, apesar de sua aparente credibilidade, nela, também, ocorrem omissões intencionais, acréscimos e manipulações de toda ordem (KOSSOY, 1989, p. 99).

Ao fotografar, o emissor obedece ao registro mental que ele mesmo criou antes do clique. Por isso e por diversos argumentos citados até aqui, a fotografia não pode ser considerada um registro fiel do real. Ainda que a fixação do suporte traga mais credibilidade aos fatos, ou, como afirma Sontag (2003), torne o ocorrido "mais real", a imagem fotográfica é uma representação. Assim como os documentos escritos, a fotografia traz pessoalidades de seu autor.

Segundo Borges (2003), a imagem fotográfica não atua como reflexo da realidade retratada, mas como mediadora. A fotografia é constituída por estilos cognitivos próprios, referentes à ordem simbólica e à linguagem metafórica. Para a autora, o registro fotográfico cria novas formas de documentar a realidade.

Mais que a palavra escrita, o desenho e a pintura, a pretensa objetividade da imagem fotográfica, veiculada nos jornais, não apenas informa o leitor sobre datas, localização, nome de pessoas envolvidas nos acontecimentos - sobre as transformações do tempo curto, como também cria verdades a partir de fantasias do imaginário quase sempre produzidas por frações da classe dominante (BORGES, 2003, p. 69).

A imagem fotográfica, enquanto meio de documentar a realidade, não cumpre apenas o papel de ilustrar a escrita, mas o de indicar costumes, hábitos e a realidade de uma determinada época. Para conhecer o passado representado na imagem fotográfica, é preciso ir além do próprio registro.

\section{O Clube do Bangue-Bangue e o Fotojornalismo de Guerra}

O Clube do Bangue-Bangue era formado pelos fotógrafos Greg Marinovich, Ken Oosterbroek, Kevin Carter e João Silva. Entre os anos em que atuou na África do Sul, o grupo se destacou pela qualidade informativa de seu trabalho e recebeu dois prêmios Pulitzer e três Ilford, homenagem destinada ao melhor repórter sul-africano do ano.

Para o arcebispo emérito da Cidade do Cabo, Desmond Tutu, o Clube do Bangue-Bangue foi um dos principais responsáveis por tornar públicos os massacres realizados no país. "Temos uma dívida imensa com eles, por sua contribuição ao frágil processo de transição da repressão para a democracia, da injustiça para a liberdade." (MARINOVICH; SILVA, 2003, p. 10). 
O grupo apresentou-se como um elemento de efetiva oposição ao sistema do apartheid. A maior parte dos registros produzidos pelos quatro fotógrafos era considerada, pelos editores sulafricanos, violenta demais para a publicação interna e, por isso, era vendida a grandes agências de comunicação internacionais como a Sygma e Associated Press.

No que confere o olhar desses profissionais em relação à segregação racial imposta no país, Marinovich era quem apresentava o sentimento mais forte de contestação. Já Oosterbroek era quem se sentia menos à vontade na presença de negros (MARINOVICH; SILVA, 2003). A respeito do grupo, sabe-se que:

\begin{abstract}
A essa altura [abril de 1994, poucos dias antes da eleição de Nelson Mandela], tínhamos nos tornado um grupo muito unido: Ken, Kevin, João e eu [Greg] - o chamado Clube do Bangue-Bangue, conforme fora sugerido anos antes. Mas, na verdade, não éramos só nós quatro. O clube se ampliara e agora incluía fotógrafos locais e estrangeiros de quem tínhamos nos tornado amigos [...]. Éramos arrogantes, elitistas e altamente competitivos. Para nós, tornou-se um espetáculo cômico, o fato de vários fotógrafos visitantes - que não conhecíamos - tentarem desesperadamente se enturmar conosco: havia meio mais fácil de conseguir acesso e fotografar a violência do que por intermédio dos rapazes do local, que conheciam o terreno e tinham todas as informações? (MARINOVICH; SILVA, 2003, p. 188-189).
\end{abstract}

Durante os quatros anos de trabalho conjunto, a relação entre eles tornou-se pessoal. Por diversos momentos, Marinovich e Silva (2003) descrevem o estado emocional a que estavam submetidos no momento do clique. O Clube do Bangue-Bangue é um exemplo clássico de fotojornalismo de guerra, em que a todo momento os profissionais corriam risco de morte. Aponta-se que a ação de Marinovich, Carter, Oosterbroek e Silva, em território sulafricano, tenha almejado inserir o leitor na realidade fotografada. Graças ao intenso convívio dos quatro, é possível perceber estruturas discursivas semelhantes na composição fotográfica.

\section{Registros Imagéticos e o Posicionamento Político}

Para o desenvolvimento desta pesquisa, foram escolhidas três fotografias de Greg Marinovich. A opção por apenas um membro do grupo devese à limitação espacial do artigo e ao destaque internacional das imagens.

Em agosto de 1990, Marinovich fotografou o ataque de um grupo de zulus, partidários do Inkatha, contra um homem suspeito de ser xhosa (figura 1). Devido à intensidade das agressões, a vítima morreu. Tempo depois, foi confirmado que o homem era da etnia pondo, sem filiação política determinada.

Figura 1 - Pondo é assassinado por militantes zulus

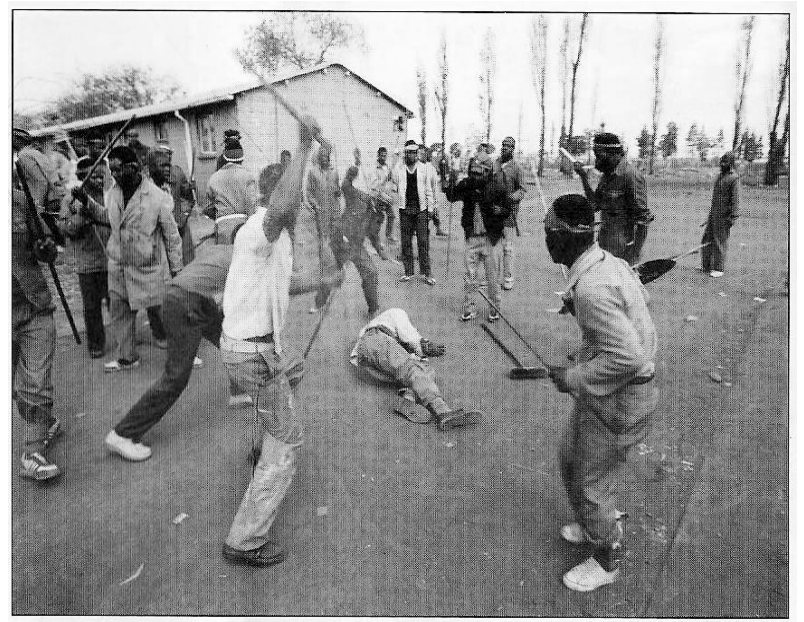

Fonte: Marinovich e Silva (2003).

A figura 1 foi uma das primeiras fotografias que Greg Marinovich registrou na Guerra dos Albergues. O fotógrafo relatou que "estava horrorizado, gritando mentalmente que aquilo não poderia estar acontecendo." (MARINOVICH; SILVA, p. 34). A imagem, também, marcou o início da carreira internacional do repórter fotográfico e seu engajamento social.

No mês seguinte, em setembro de 1990, Greg Marinovich afirmou que foi procurado pelas autoridades sul-africanas, após documentar fotograficamente o assassinato de Lindsaye 
Tshabalala (figuras 2 e 3 ), suposto militante Inkatha, por partidários do CNA. As fotografias ganharam as páginas de todo o mundo e venceram o prêmio Pulitzer de Reportagem em 1991. O fotógrafo se negou a entregar os negativos ao Governo, já que, no mês anterior, havia registrado um episódio de extrema violência em que zulus mataram um xhosa, mas não foi procurado para testemunhar o fato (figura 1).

Figura 2 - Partidário do CNA prepara-se para esfaquear Lindsaye Tshabalala

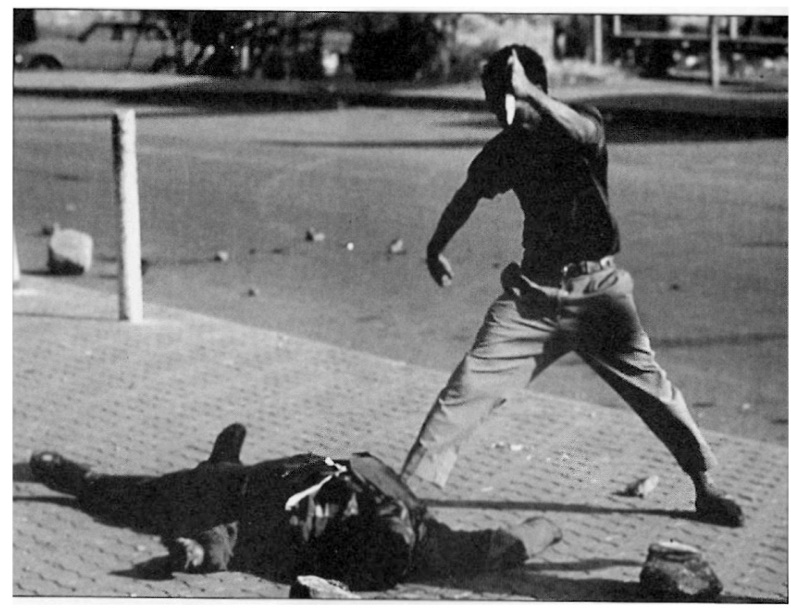

Fonte: Marinovich e Silva (2003).

Figura 3 - Com o corpo em chamas, Lindsaye Tshabalala é atingido com um golpe de machete no crânio

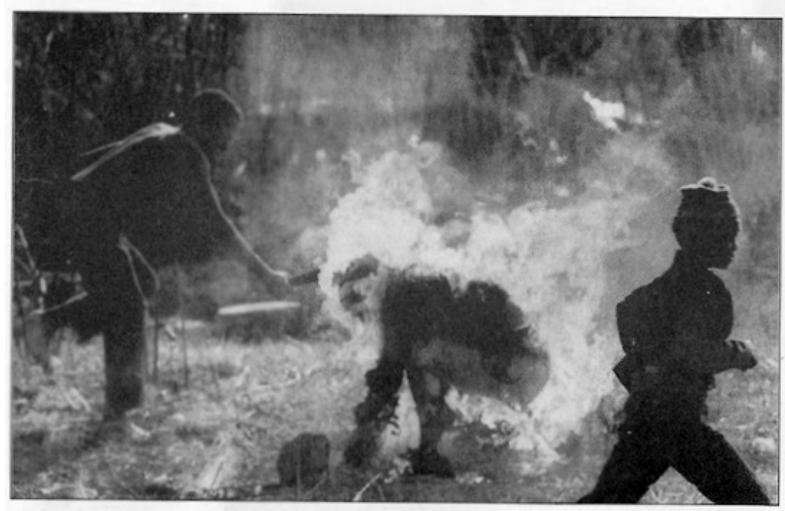

Fonte: Marinovich e Silva (2003).
Para Marinovich e Silva (2003), o Governo tinha o intuito de utilizar as figuras 2 e 3 - em que xhosas apareciam em atos de violência - para enfraquecer a candidatura de Nelson Mandela à presidência, já que o partido africânder mantinha alianças políticas com o Inkatha.

$\mathrm{Na}$ África do Sul, a violência das fotos teve um efeito explosivo. O governo sul-africano viu na morte de Lindsaye Tshabalala a oportunidade perfeita de retratar o CNA como um grupo de assassinos a quem jamais se poderia confiar a liderança do país. Em poucos dias, a polícia procurou o escritório da AP em Joanesburgo para saber se eu entregaria as fotos, para que pudessem identificar os criminosos. Também, seria necessário eu comparecer a um tribunal para atestar a autenticidade das fotos, a fim de que elas pudessem ser apresentadas como provas. A polícia não havia contatado a $\mathrm{AP}$ nem os jornais locais, por causa das minhas fotos dos guerreiros do Inkatha matando o suposto partidário do CNA no mês anterior - presumivelmente não era de interesse do Estado sul-africano processar aliados (MARINOVICH; SILVA, 2003, p. 53).

É possível observar, pela leitura das três fotografias e das memórias de Marinovich e Silva (2003), que o posicionamento do grupo era contrário à ordem do apartheid. Em alguns momentos, durante a construção do texto, Greg Marinovich informa que, "ao contrário de todos nós, Ken não se sentia à vontade com negros" (MARINOVICH; SILVA, 2003, p. 72), para demarcar sua noção de contrariedade à atitude do companheiro, ele completa a frase dizendo "e, por causa disso, no começo, eu evitava trabalhar muito com ele" (MARINOVICH; SILVA, 2003, p. 72). Essa demarcação política é recorrente na narrativa, principalmente, no que diz respeito a Greg Marinovich ${ }^{5}$.

Neste artigo, a posição política não foi demarcada, no que diz respeito à filiação partidária ou à militância, mas a postura dos fotógrafos em relação ao apartheid. Vale ressaltar que a forma de governo implantada na África do Sul afetou, de uma maneira muito intensa, o seu desenvolvimento político, econômico e social. Magnoli (1998) chega a dizer que

\footnotetext{
${ }^{5}$ Esse comportamento é mais perceptível em Marinovich, já que o livro foi escrito por ele. A função de João Silva foi mais de auxiliar na organização e na condução dos fatos.
} 
o apartheid não confrontou apenas brancos contra negros, mas afetou toda a sociedade. Considerase que a recusa de Marinovich, em entregar as fotografias ao Governo sul-africano, não teve o mérito de proteger o CNA, já que as fotografias não deixaram de ser publicadas. O que Greg Marinovich se recusou a fazer foi ser testemunha de acusação contra os militantes de oposição. O objetivo do fotógrafo era o de tornar público os atos de violência. O fotógrafo afirmou que a entrega do material ao Estado dificultaria o processo de transição para a democracia multirracial e não acabaria com os confrontos entre as tribos negras.

Entre os motivos, para justificar sua opção em não entregar as fotografias ao Governo, Marinovich destacou sua oposição ao regime do apartheid e à segregação racial e, também, sua segurança profissional. O fotógrafo deixou claro que ele e outros profissionais poderiam ser mortos enquanto trabalhavam, sob acusação de apoiar o Estado (MARINOVICH; SILVA, 2003).

O Clube do Bangue-Bangue, também, esforçouse para desmentir a versão oficial sobre a realidade sul-africana e comprovar o apoio estatal aos zulus. Em vários momentos, as fotografias mais violentas eram apontadas pelo Governo como falsas.

Os editores de muitas organizações jornalísticas nacionais e estrangeiras ainda aceitavam como verdadeiros os relatórios policiais, embora fosse evidente que a polícia era parte do problema. [...] Mas a AP e quase todos os veículos de imprensa optaram por acreditar na propaganda do governo. O público teria sido informado sobre mais um massacre, por meio das pessoas que, na verdade, estavam envolvidas em muitas das mortes, conforme ficaria provado anos mais tarde. A impressão era que o público nacional e internacional parecia bastante propenso a acreditar que as pessoas que, às vezes, se vestiam com peles e não sabiam falar inglês corretamente deviam ser gente bárbara, enquanto os políticos e os funcionários brancos, que falavam com tanta lógica, mantinham os trens circulando no horário e não poderiam jamais estar implicados nos crimes (MARINOVICH; SILVA, 2003, p. 86).
A violência documentada nas figuras 1,2 e 3 revelou ao mundo a guerra civil interna que poderia eclodir a qualquer momento na África do Sul. Aponta-se, portanto, que os fotógrafos não tomaram partido nos confrontos entre as tribos negras, eles registraram todos os personagens na violência local. O objetivo principal era comprovar que a instabilidade social era fruto do apartheid. A postura do Clube do Bangue-Bangue e, mais especificamente, a de Greg Marinovich, mostrou que o fotojornalista tem um papel político.

\section{Considerações Finais}

Com base nas imagens, é possível apontar a oposição direta do Clube do Bangue-Bangue ao apartheid, a segregação racial e aos conflitos internos. As fotografias, assim como os relatos verbais do grupo, estão fortemente marcados pela subjetividade dos seus autores, no entanto, estes relatos encontram conformidade com os registros historiográficos da África do Sul.

$\mathrm{O}$ próprio ato dos fotógrafos em registrar a Guerra dos Albergues já se destacava como um ato de oposição ao Estado, já que os conflitos internos não eram noticiados por grande parte dos veículos de comunicação sul-africanos. As imagens enviadas ao exterior, por meio das agências de notícias internacionais, trouxeram visibilidade aos conflitos internos. O Clube do Bangue-Bangue tornou-se referência entre os fotógrafos, principalmente, pela qualidade técnica do seu trabalho, tendo em vista que receberam prêmios de destaque no ramo.

Os registros do grupo, tanto os imagéticos quanto os verbais, assim como a historiografia e os conceitos fotográficos aplicados neste trabalho não são suficientes para documentar o apartheid, nem mesmo o recorte de quatro anos, a que este artigo timidamente se dispõe a fazer. Não foi intuito da pesquisa classificar o grupo em uma corrente 
político-partidária, mas demonstrar o trabalho jornalístico como um ato político e ideológico de seu emissor. Qual a maior contribuição do Clube do Bangue-Bangue, então? A de mostrar ao mundo o que estava oculto. Ou o que Marinovich costumava acreditar que "estávamos convencidos de que a única maneira de cessar aquela matança era mostrar aqueles mortos, mostrar o que realmente significava aquela contagem diária de corpos." (MARINOVICH; SILVA, 2003, p. 85).

\section{Referências}

BONI,P.C.Odiscursofotográfico:aintencionalidade de comunicação no fotojornalismo. 2000. Tese (Doutorado em Ciências da Comunicação) - Escola de Comunicações e Artes, Universidade de São Paulo, São Paulo.

BORGES, M. E. L. História e fotografia. Belo Horizonte: Autêntica, 2003.

CARLIN, J. Conquistando o inimigo: Nelson Mandela e o jogo que uniu a África do Sul. Rio de Janeiro: Sextante, 2009.

KOSSOY, B. Fotografia e história. São Paulo: Ática, 1989.

MAGNOLI, D. África do Sul: capitalismo e apartheid. 4. ed. São Paulo: Contexto, 1998.

MARINOVICH, G.; SILVA, J. O clube do banguebangue: instantâneos de uma guerra oculta. São Paulo: Companhia das Letras, 2003.

MARTINS, J. S. Sociologia da fotografia e da imagem. São Paulo: Contexto, 2008.

SONTAG, S. Diante da dor dos outros. São Paulo: Companhia das Letras, 2003. 